\title{
Multiple Criteria ABC Analysis with FCM Clustering
}

\author{
Gulsen Aydin Keskin ${ }^{1}$ and Coskun Ozkan ${ }^{2}$ \\ ${ }^{1}$ Department of Industrial Engineering, Faculty of Engineering, Kocaeli University, Umuttepe Campus, 41380 Kocaeli, Turkey \\ ${ }^{2}$ Department of Industrial Engineering, Faculty of Engineering, Yildiz Technical University, 34349 Istanbul, Turkey
}

Correspondence should be addressed to Gulsen Aydin Keskin; gaydin@kocaeli.edu.tr

Received 13 August 2012; Revised 29 October 2012; Accepted 12 November 2012

Academic Editor: Josefa Mula

Copyright (C) 2013 G. Aydin Keskin and C. Ozkan. This is an open access article distributed under the Creative Commons Attribution License, which permits unrestricted use, distribution, and reproduction in any medium, provided the original work is properly cited.

\begin{abstract}
The number of stock keeping units (SKUs) possessed by organizations can easily reach quite a few. An inventory management policy for each individual SKU is not economical to design. ABC analysis is one of the conventionally used approaches to classify SKUs. In the classical method, the SKUs are ranked with respect to the descending order of the annual dollar usage, which is the product of unit price and annual demand. The few of the SKUs that have the highest annual dollar usage are in group A and should be taken into account mostly; the SKUs with the least annual dollar usage are in group C and should be taken into account least; the remaining SKUs are in group B. In this study, we proposed fuzzy c-means (FCM) clustering to a multicriteria $\mathrm{ABC}$ analysis problem to help managers to make better decision under fuzzy circumstancse. The obtained results show that the FCM is a quite simple and an easily adaptable method to inventory management.
\end{abstract}

\section{Introduction}

Inventory control is a well-known problem in operations research. Several models have been developed to solve inventory problems. In business, companies have hundreds of different types of materials. Therefore, it is easy to lose control of managing the materials. Inventory classification using $\mathrm{ABC}$ analysis is one of the most widely used techniques in organizations. $\mathrm{ABC}$ classification allows an organization to separate stock keeping units (SKUs) into three groups: A, the most important; B, important; and C, the least important. The purpose of classifying items into groups is to establish appropriate levels of control over each item [1,2]. The major advantage of $\mathrm{ABC}$ analysis is the easiness of use and simplicity to understand. The items are classified according to the annual use value, which is the product of annual demand and the average unit price [3]

The classification of items into A, B, and C groups has generally been implemented according to one criterion. For inventory items, the criterion is frequently the annual dollar usage of the item. However, it has been generally recognized that the traditional $\mathrm{ABC}$ analysis has a serious drawback that may inhibit the effectiveness of the procedure in some situations. Using one criterion only may create problems of significant financial loss. For example, class $\mathrm{C}$ items with long lead time or class A items prone to obsolescence may incur financial losses due to a possible interruption of production and/or huge inventory levels. Therefore, it has been proposed that multicriteria ABC classification, such as lead time, criticality of a stockout of the item, the rate of obsolescence, the scarcity, substitutability, and order size requirement of the item, can provide a more comprehensive managerial control and to take other important criteria into consideration $[2,4$, 5].

Complex computational tools are needed for traditional multicriteria $\mathrm{ABC}$ classification. One of them is the matrixbased methodology. At this methodology, a joint criteria matrix is developed in the case of two criteria. However, the methodology is relatively difficult to use when more criteria have to be considered [6]. The other technique used to weigh the criteria is the analytic hierarchy process (AHP) $[1,2,7]$. The main idea of AHP is to derive a single scalar measure of importance of inventory items by subjectively rating the criteria and/or the inventory items. The single most important issue associated with AHP-based studies is the subjectivity involved in the analysis [3]. 
In this paper, we are concerned with the multicriteria classification method aimed to facilitate inventory management. The classification method is proposed through a case study of an automative company. Being distinct from the techniques used for multicriteria $\mathrm{ABC}$ analysis, the criteria are not weighed in this method. Therefore, this method does not involve subjectivity. In addition, unlike other methods, our method not only determines the matching to any of the clusters but also gives the membership degrees to all clusters. These are our contributions to the literature.

The aim of this study is to develop a decision-making approach to the $\mathrm{ABC}$ analysis method, which is a multicriteria decision-making problem. The remainder of the paper is organized as follows: ABC analysis is described in Section 2. In Section 3 fuzzy c-means (FCM) clustering is explained. In Section 4, the FCM is applied to a real life problem. Finally, conclusions are drawn in Section 5.

\section{ABC Analysis}

The conventional ABC classification based on Pareto principle, developed at General Electric during the 1950s, is the most popular method to classify the items in inventory [4]. In this classification, inventory items are ordered descendingly with respect to their annual dollar usage values. The relatively small number of items at the top of the list (approx. 10\%) controlling the majority of the total annual dollar usage constitute class A, the majority of the items at the bottom of the list (approx. 60\%) controlling a relatively small portion of the total annual dollar usage constitute class $\mathrm{C}$, and the items between the two classes constitute class B (approx. $30 \%)$. This classification may not always be accurate, but it has been found too close to the existing occurrence in companies with remarkable accuracy. Class A inventory items require cautious inventory control because they represent a large percentage of the total dollar value of the inventory. This state requires certain demand forecasts and detailed record keeping. Class $\mathrm{C}$ inventory items should receive a flexible control. Class B items should have a control effort that lies between $\mathrm{A}$ and $\mathrm{C}$ categories $[1,2]$.

Because of its easy-to-implement nature, applicability to numerous situations, empirically observed benefits, and remarkable effectiveness in many inventory systems, this approach is still popularly used in practice. However, the method has a serious drawback that may inhibit the effectiveness of the procedure in some situations. The criterion used in the conventional $\mathrm{ABC}$ classification is the annual dollar usage, so using one criterion may create problems of significant financial loss $[4,8]$. Thus, the inventory control problem becomes a multicriteria inventory classification that has been studied by some researchers. In the literature, some of the considered criteria include inventory cost, criticality, lead time, commonality, obsolescence, substitutability, number of requests for the item in a year, scarcity, durability, substitutability, repairability, order size requirement, stockability, demand distribution, and stockout penalty cost $[2,3]$.

2.1. Related Research. In recent years, several new multicriteria approaches to inventory classification have been introduced but all have some drawbacks. Classical ABC classification approach on two criteria is a step forward in multicriteria ABC classification. However, the methodology is relatively difficult to use when more criteria have to be considered. There is no obvious way to extend the procedure to more than two criteria [2]. The first paper about ABC analysis was presented by Flores and Whybark in 1986 [9]. Affected from this study, Chen et al. [8] have presented a casebased multicriteria ABC analysis by accounting additional criteria, such as lead time and criticality of SKUs, to provide managerial flexibility.

In 1990, a methodology based on statistical clustering was proposed by Ernst and Cohen. But this approach requires substantial data, the use of factor analysis, and a clustering procedure, which may render it impractical in typical stockroom environments. Furthermore, the clusters themselves must be reevaluated in order to classify new stock items, so there is a chance that previously classified stock may end up being classified differently every time new items are added, and this may disturb the inventory control procedure. In short, the model may be too sophisticated for the average manager [1].

The AHP process has also been proposed by several authors for ABC classification [6] Cakir and Canbolat [7] have proposed AHP with integrating fuzzy technique to solve the multicriteria inventory classification problem. The advantage of the AHP is that it can incorporate many criteria and its ease of use on a massive accounting and measurement system. One of the important drawbacks of the method is that a significant amount of subjectivity is involved in pairwise comparisons of criteria, rating levels, and assigning a rating level and associated weights $[1,2]$.

Artificial intelligence is another method for multicriteria inventory classification. Guvenir and Erel [4] have presented a new approach using AHP technique and genetic algorithm to multicriteria classification. Artificial neural network is another technique, which is applicable to the classification process. Partovi and Anandarajan [1] have proposed an artificial neural network (ANN) by utilizing two learning methods in the ANN named back-propagation and genetic algorithms for ABC classification of SKUs. Ramanathan [3], has proposed a simple weighted linear optimization model to address the multicriteria inventory classification problem, which is similar to data envelopment analysis (DEA). Zhou and Fan [10] have presented an extended version of the Ramanathan's model by incorporating some balancing features for multicriteria $\mathrm{ABC}$ inventory classification. The classification results are compared with those of Bayes and other fuzzy classifiers. It is shown that the proposed method is superior to them. Chu et al. [2] have proposed a new inventory control approach by integrating $\mathrm{ABC}$ and fuzzy classification.

Different from what is mentioned previously, $\mathrm{Ng}$ [11] has proposed an alternative weight linear optimization model for multicriteria inventory classification by using the ABC principle. Hadi-Vencheh [12] has presented an extended version of the $\mathrm{Ng}$-model which is a simple classifier for multicriteria ABC analysis. Al Kattan and Bin Adi [13] have 
TABLE 1: The data set of all items at the company.

\begin{tabular}{|c|c|c|c|c|}
\hline SKUs & Average unit cost & Annual dollar usage & Critical factor & Lead time \\
\hline$S 1$ & 47.24 & 482.40 & 1.00 & 3.00 \\
\hline S2 & 35.64 & 389.00 & 1.00 & 7.00 \\
\hline S3 & 98.25 & 357.50 & 1.00 & 2.00 \\
\hline S4 & 15.58 & 272.60 & 0.01 & 2.00 \\
\hline S5 & 34.87 & 462.80 & 0.50 & 3.00 \\
\hline S6 & 56.87 & 349.70 & 0.01 & 4.00 \\
\hline S7 & 34.25 & 286.00 & 0.50 & 5.00 \\
\hline S8 & 42.40 & 267.50 & 0.01 & 3.00 \\
\hline S9 & 55.82 & 467.32 & 1.00 & 2.00 \\
\hline S10 & 24.25 & 382.60 & 0.50 & 1.00 \\
\hline S11 & 54.25 & 99.56 & 1.00 & 5.00 \\
\hline S12 & 23.57 & 187.25 & 0.50 & 4.00 \\
\hline S13 & 47.50 & 101.50 & 1.00 & 8.00 \\
\hline S14 & 65.34 & 657.45 & 0.50 & 3.00 \\
\hline S15 & 57.64 & 547.25 & 1.00 & 2.00 \\
\hline S16 & 102.50 & 564.75 & 0.50 & 1.00 \\
\hline S17 & 23.57 & 458.25 & 0.01 & 5.00 \\
\hline S18 & 40.21 & 182.60 & 0.50 & 7.00 \\
\hline S19 & 17.54 & 356.45 & 0.01 & 2.00 \\
\hline S20 & 34.15 & 264.25 & 0.50 & 3.00 \\
\hline S21 & 11.35 & 278.46 & 1.00 & 5.00 \\
\hline S22 & 70.00 & 105.67 & 0.50 & 3.00 \\
\hline S23 & 51.21 & 472.16 & 1.00 & 7.00 \\
\hline S24 & 68.54 & 266.84 & 0.50 & 8.00 \\
\hline S25 & 51.17 & 189.18 & 0.01 & 1.00 \\
\hline S26 & 12.58 & 350.15 & 0.01 & 1.00 \\
\hline S27 & 37.59 & 458.56 & 0.01 & 1.00 \\
\hline S28 & 24.25 & 284.16 & 0.01 & 5.00 \\
\hline S29 & 103.50 & 187.54 & 0.50 & 3.00 \\
\hline S30 & 20.00 & 256.18 & 1.00 & 1.00 \\
\hline S31 & 75.18 & 358.95 & 0.50 & 5.00 \\
\hline S32 & 18.25 & 452.10 & 1.00 & 3.00 \\
\hline S33 & 24.80 & 154.15 & 0.50 & 2.00 \\
\hline S34 & 26.27 & 127.48 & 0.01 & 4.00 \\
\hline S35 & 15.20 & 175.35 & 0.01 & 2.00 \\
\hline S36 & 12.50 & 250.14 & 1.00 & 2.00 \\
\hline S37 & 12.54 & 187.70 & 0.50 & 8.00 \\
\hline S38 & 85.00 & 148.25 & 0.50 & 4.00 \\
\hline S39 & 64.30 & 256.48 & 0.01 & 4.00 \\
\hline S40 & 20.60 & 457.10 & 0.01 & 3.00 \\
\hline S41 & 46.20 & 154.15 & 1.00 & 1.00 \\
\hline S42 & 14.80 & 87.16 & 0.01 & 2.00 \\
\hline S43 & 26.55 & 96.58 & 0.50 & 1.00 \\
\hline S44 & 16.78 & 102.11 & 0.01 & 2.00 \\
\hline S45 & 64.20 & 132.60 & 1.00 & 5.00 \\
\hline
\end{tabular}

proposed a method to reduce total inventory cost by the combination of $\mathrm{ABC}$ and 123 analysis.

\section{Fuzzy C-Means (FCM) Algorithm}

The fuzzy c-means (FCM) algorithm is a useful tool for clustering, which partitions a real $n$-dimensional dataset into $c$ fuzzy clusters by minimizing the clustering objective function to describe an underlying structure within the data [14].

Although the final version of the FCM algorithm was introduced by Bezdek, the origins of the algorithm are traced back to Dunn [15]. Afterwards, several studies have used the FCM algorithm in many engineering fields such as partmachine grouping in cellular manufacturing [16], image segmentation $[17,18]$, new product development (NPD) 
TABLE 2: Normalized value data set of all items at the company.

\begin{tabular}{|c|c|c|c|c|}
\hline SKUs & Average unit cost & Annual dollar usage & Critical factor & Lead time \\
\hline $\mathrm{S} 1$ & 0.39 & 0.69 & 1.00 & 0.29 \\
\hline S2 & 0.26 & 0.53 & 1.00 & 0.86 \\
\hline S3 & 0.94 & 0.47 & 1.00 & 0.14 \\
\hline S4 & 0.05 & 0.33 & 0.01 & 0.14 \\
\hline S5 & 0.26 & 0.66 & 0.49 & 0.29 \\
\hline S6 & 0.49 & 0.46 & 0.01 & 0.43 \\
\hline S7 & 0.25 & 0.35 & 0.49 & 0.57 \\
\hline S8 & 0.34 & 0.32 & 0.01 & 0.29 \\
\hline S9 & 0.48 & 0.67 & 1.00 & 0.14 \\
\hline $\mathrm{S} 10$ & 0.14 & 0.52 & 0.49 & 0.01 \\
\hline S11 & 0.47 & 0.02 & 1.00 & 0.57 \\
\hline S12 & 0.13 & 0.18 & 0.49 & 0.43 \\
\hline S13 & 0.39 & 0.03 & 1.00 & 1.00 \\
\hline S14 & 0.59 & 1.00 & 0.49 & 0.29 \\
\hline S15 & 0.50 & 0.81 & 1.00 & 0.14 \\
\hline S16 & 0.99 & 0.84 & 0.49 & 0.01 \\
\hline S17 & 0.13 & 0.65 & 0.01 & 0.57 \\
\hline S18 & 0.31 & 0.17 & 0.49 & 0.86 \\
\hline S19 & 0.07 & 0.47 & 0.01 & 0.14 \\
\hline S20 & 0.25 & 0.31 & 0.49 & 0.29 \\
\hline S21 & 0.01 & 0.34 & 1.00 & 0.57 \\
\hline S22 & 0.64 & 0.03 & 0.49 & 0.29 \\
\hline S23 & 0.43 & 0.68 & 1.00 & 0.86 \\
\hline S24 & 0.62 & 0.32 & 0.49 & 1.00 \\
\hline S25 & 0.43 & 0.18 & 0.01 & 0.01 \\
\hline S26 & 0.01 & 0.46 & 0.01 & 0.01 \\
\hline S27 & 0.28 & 0.65 & 0.01 & 0.01 \\
\hline S28 & 0.14 & 0.35 & 0.01 & 0.57 \\
\hline S29 & 1.00 & 0.18 & 0.49 & 0.29 \\
\hline S30 & 0.09 & 0.30 & 1.00 & 0.01 \\
\hline S31 & 0.69 & 0.48 & 0.49 & 0.57 \\
\hline S32 & 0.07 & 0.64 & 1.00 & 0.29 \\
\hline S33 & 0.15 & 0.12 & 0.49 & 0.14 \\
\hline S34 & 0.16 & 0.07 & 0.01 & 0.43 \\
\hline S35 & 0.04 & 0.15 & 0.01 & 0.14 \\
\hline S36 & 0.01 & 0.29 & 1.00 & 0.14 \\
\hline S37 & 0.01 & 0.18 & 0.49 & 1.00 \\
\hline S38 & 0.80 & 0.11 & 0.49 & 0.43 \\
\hline S39 & 0.57 & 0.30 & 0.01 & 0.43 \\
\hline S40 & 0.10 & 0.65 & 0.01 & 0.29 \\
\hline S41 & 0.38 & 0.12 & 1.00 & 0.01 \\
\hline S42 & 0.04 & 0.01 & 0.01 & 0.14 \\
\hline S43 & 0.16 & 0.02 & 0.49 & 0.01 \\
\hline S44 & 0.06 & 0.03 & 0.01 & 0.14 \\
\hline S45 & 0.57 & 0.08 & 1.00 & 0.57 \\
\hline
\end{tabular}

[19], health sector [20], geology [21], data envelopment analysis [22], business [23], and so on.

In the case of the well-separated data group, the hard clustering approach can be a natural solution. When the clusters overlap and some of the data partially belong to several clusters as seen in Figure 1, the fuzzy clustering is a natural way to describe this situation, and the membership degree of a data object to a cluster is a value between the interval $[0,1]$.

At FCM, the clusters are defined with respect to cluster numbers $(c)$ and initial membership values of the input vector. The memberships of the clusters are defined with the corresponding membership values. Also at the algorithm, 


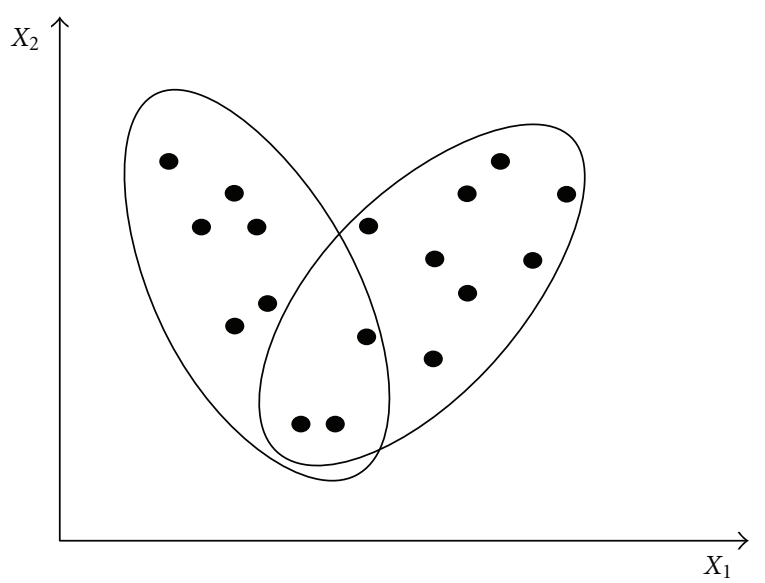

FIGURE 1: Illustration of fuzzy clustering [24].

clusters are described by prototypes which represent the cluster centers.

It is an iteratively optimal algorithm based on the iterative minimization of the objective function in (1) as follows:

$$
J_{m}(U, V)=\sum_{k=1}^{n} \sum_{i=1}^{c} u_{k i}^{m}\left\|x_{k}-v_{i}\right\|^{2} .
$$

In (1), $n$ is the total number of data vectors in a given data set and $c$ is the number of clusters; $X=\left\{x_{1}, x_{2}, \ldots, x_{n}\right\} \subset$ $R^{s}$ and $V=\left\{v_{1}, v_{2}, \ldots, v_{c}\right\} \subset R^{s}$ are the feature data and cluster centers; $U=\left(u_{k i}\right)_{n * c}$ is a fuzzy partition matrix that is composed of the membership of each feature vector $x_{k}$ in each cluster $i$. Here, $u_{k i}$ should satisfy $\sum_{i=1}^{c} u_{k i}=1$ for $k=$ $1,2, \ldots, n$ and $u_{k i} \geq 0$ for all $i=1,2, \ldots, c$ and $k=1,2, \ldots, n$. The exponent $m>1$ in (1) is a parameter called fuzzifier. To minimize (1), the cluster centers $v_{i}$ and membership matrix $U$ need to be calculated with regards to the following iterative formula:

$$
\begin{gathered}
u_{k i} \\
= \begin{cases}\left(\sum_{j=1}^{c}\left(\frac{\left\|x_{k}-v_{i}\right\|}{\left\|x_{k}-v_{j}\right\|}\right)^{2 /(m-1)}\right)^{-1} & \text { if }\left\|x_{k}-v_{j}\right\|>0, \\
1, & \text { if }\left\|x_{k}-v_{i}\right\|=0, \\
0, & \text { if } \exists j \neq i\left\|x_{k}-v_{j}\right\|=0,\end{cases} \\
\text { for } K=1, \ldots, n, \quad i=1, \ldots, c, \\
v_{i}=\frac{\sum_{k=1}^{n} u_{k i}^{m} \cdot x_{k}}{\sum_{i=1}^{N} u_{k i}^{m}}, \quad i=1,2, \ldots, c .
\end{gathered}
$$

\begin{tabular}{|c|c|c|c|}
\hline SKUs & $\mathrm{C} 1$ & $\mathrm{C} 2$ & C3 \\
\hline S1 & 0.120297 & 0.044415 & 0.835287 \\
\hline S2 & 0.482047 & 0.116516 & 0.401437 \\
\hline S3 & 0.312767 & 0.13446 & 0.552773 \\
\hline S4 & 0.045124 & 0.919403 & 0.035473 \\
\hline S5 & 0.29339 & 0.25688 & 0.44973 \\
\hline S6 & 0.221803 & 0.649321 & 0.128876 \\
\hline S7 & 0.73305 & 0.125228 & 0.141722 \\
\hline S8 & 0.055329 & 0.910642 & 0.034029 \\
\hline S9 & 0.127868 & 0.055433 & 0.816699 \\
\hline S10 & 0.225196 & 0.380499 & 0.394306 \\
\hline S11 & 0.565756 & 0.102472 & 0.331772 \\
\hline S12 & 0.527109 & 0.27132 & 0.201571 \\
\hline S13 & 0.567224 & 0.143353 & 0.289423 \\
\hline S14 & 0.299279 & 0.241065 & 0.459655 \\
\hline S15 & 0.175279 & 0.087093 & 0.737628 \\
\hline S16 & 0.305682 & 0.261788 & 0.43253 \\
\hline S17 & 0.23184 & 0.611386 & 0.156774 \\
\hline S18 & 0.696526 & 0.149756 & 0.153718 \\
\hline S19 & 0.062379 & 0.884495 & 0.053126 \\
\hline S20 & 0.435864 & 0.284404 & 0.279732 \\
\hline S21 & 0.414061 & 0.128463 & 0.457476 \\
\hline S22 & 0.524111 & 0.227003 & 0.248886 \\
\hline S23 & 0.444989 & 0.119633 & 0.435377 \\
\hline S24 & 0.620943 & 0.16766 & 0.211397 \\
\hline S25 & 0.142157 & 0.747277 & 0.110566 \\
\hline S26 & 0.098581 & 0.80764 & 0.093779 \\
\hline S27 & 0.143794 & 0.708718 & 0.147487 \\
\hline S28 & 0.18746 & 0.714468 & 0.098072 \\
\hline S29 & 0.449008 & 0.232609 & 0.318382 \\
\hline S30 & 0.244025 & 0.145713 & 0.610262 \\
\hline S31 & 0.604867 & 0.142195 & 0.252938 \\
\hline S32 & 0.202419 & 0.094825 & 0.702756 \\
\hline S33 & 0.326855 & 0.407832 & 0.265313 \\
\hline S34 & 0.15908 & 0.758182 & 0.082737 \\
\hline S35 & 0.076982 & 0.866962 & 0.056056 \\
\hline S36 & 0.273608 & 0.143173 & 0.583219 \\
\hline S37 & 0.527114 & 0.247646 & 0.225239 \\
\hline S38 & 0.567682 & 0.188999 & 0.243319 \\
\hline S39 & 0.262399 & 0.601451 & 0.136149 \\
\hline S40 & 0.132168 & 0.756197 & 0.111636 \\
\hline S41 & 0.292748 & 0.140513 & 0.566739 \\
\hline S42 & 0.137553 & 0.76635 & 0.096096 \\
\hline S43 & 0.299306 & 0.421279 & 0.279415 \\
\hline S44 & 0.123892 & 0.789745 & 0.086362 \\
\hline S45 & 0.559776 & 0.096093 & 0.344132 \\
\hline
\end{tabular}

The procedure of the Fuzzy C-Means (FCM) algorithm is as seen hereinafter.

Step 1. Input the number of clusters $c$, the fuzzifier $m$, and the distance function $\|\cdot\|$.

Step 2. Initialize the cluster centers $v_{i}^{0}(i=1,2, \ldots, c)$.
TABLE 3: The cluster memberships of all items after FCM.

Step 3. Compute $u_{k i}(k=1,2, \ldots n ; i=1,2, \ldots, c)$ by using (2).

Step 4. Compute $v_{i}^{1}(i=1,2, \ldots, c)$ by using (3). 
TABLE 4: Cluster members and labels.

\begin{tabular}{lcr}
\hline Labels & Cluster members & Mean of each cluster \\
\hline A & S2, S7, S11, S12, S13, S18, S20, S22, S23, S24, S29, S31, S37, S38, S45 & 2.00 \\
B & S1, S3, S5, S9, S10, S14, S15, S16, S21, S30, S32, S36, S41 & 1.96 \\
C & S4, S6, S8, S17, S19, S25, S26, S27, S28, S33, S34, S35, S39, S40, S42, S43, S44 & 0.78 \\
\hline
\end{tabular}

Step 5. If $\max _{1 \leq i \leq c}\left(\left\|v_{i}^{0}-v_{i}^{1}\right\| /\left\|v_{i}^{1}\right\|\right) \leq \varepsilon$, then go to Step 6; else let $v_{i}^{0}=v_{i}^{1}(i=1,2, \ldots, c)$ and go to Step 3 .

Step 6. Output the clustering results: cluster centers $v_{i}^{1}(i=$ $1,2, \ldots, c)$, membership matrix $U$, and, in some applications, the elements of each cluster $i$, that is, all the $x_{k}$ such that $u_{k i}>$ $u_{k j}$ for all $j \neq k$.

Step 7. Stop [25].

MATLAB R2010a is used to perform FCM ABC analysis methodology mentioned previously. In the following section, a real life problem has been introduced, and the application of the FCM algorithm for $\mathrm{ABC}$ analysis has been explained.

\section{Numerical Example}

In this study, an alternative ABC analysis based on FCM is proposed for an automotive company. In the proposed method, the SKUs are clustered with FCM. Thus, the items are separated to different clusters according to their attributes. The major advantage of FCM is not only attaching data objects to decisively one cluster but also determining the membership degrees to all other formed clusters. The SKU with high membership degree indicates the characteristic of cluster well more than the other members.

The empirical investigation for this study was carried out by using a real life data obtained from an automotive company located in Turkey. A data set containing 45 items as seen in Table 1 was used to design the frame of the study. Each data represented the classification of items with regard to four attributes: average unit cost, annual dollar usage, critical factor, and lead time. These attributes were defined based on the literature review and the opinions of the company managers.

As it is seen in Table 1, the variables of the average unit cost and the annual dollar usage are much higher than the variables of the critical factor and the lead time. Therefore, this study includes preprocessing. In the preprocessing part, we normalize the data set to state all criteria in the same way.

Normalized data are calculated according to the following equation:

$$
N I_{i, j}=\frac{I(i, j)-\min (j)}{\max (j)-\min (j)},
$$

where $I$ is the input value, $N I$ is the normalized value, $i$ is the number of items, and $j$ represents the criterion number [26]. Thus, Table 2 is obtained.

After executing the FCM code in Matlab, the membership degrees of the SKUs to the clusters are obtained. Table 3 presents the membership degrees of each item to all clusters. For instance, item S1 belongs to clusters C1, C2, and C3 with membership degrees $0.120297,0.044415$, and 0.835287 , respectively. See Tables 1,2 , and 3 .

After classifying the materials by these attributes, the next step is labeling them as A, B, and C as seen in Table 4. Labeling of the classes is calculated in three steps. At the first step, normalized criteria values are summed up for each SKU. Secondly, the SKU criteria values in the same cluster are summed up. Finally, an average value is obtained by dividing the total value of each cluster by the number of SKUs. The cluster with the highest mean is labeled as A, the second cluster is labeled as $\mathrm{B}$, and the lowest is labeled as $\mathrm{C}$.

As it is seen in Tables 3 and 4, all items are attached to clusters with regard to the highest membership degrees. For instance, S2 is attached to the cluster A with 0,482047, and S1 is attached to the cluster B with 0,835287 membership degree. In addition to this, when we examined S10, we noticed that as a close membership degree, this item belongs to cluster $\mathrm{C}$ with a membership degree of 0,380499 and also belongs to cluster B with a membership degree of 0,394306 . Here, it should be considered that this item could take part at cluster $\mathrm{C}$ depending on decision maker and conditions (i.e., lead time, cost, frequency of use, etc.). Another subject to be discussed is about items S2 and S7. The membership degree of S2 to cluster A is 0,482047 and S7 is 0,73305 . Under this circumstance, it can be said that $\mathrm{S} 7$ represents cluster A better than S2.

As seen from Table 4, the method clusters items 2, 7, 11, $12,13,18,20,22,23,24,29,31,37,38$, and 45 as cluster A that required the highest attention. Therefore, the company should have to pay more attention to this type of SKUs.

\section{Discussion and Conclusion}

Several methods are used for inventory classification. Classification has emerged as an important decision-making tool in business life such as credit scoring and classifying inventory items [2].

At conventional inventory classification, the classification analysis is based on a single criterion, the annual usage cost, which is simply the product of annual usage and dollar value per unit item. Although it is very straightforward and financially viable to apply such an analysis, the method has some quirks. Decision makers relying on this traditional analysis ignore some very crucial qualitative criteria. To overcome the limitations of the traditional classification analysis, many researchers concentrated on incorporating multicriteria judgments into the inventory classification procedure [7] such as average unit cost, criticality, and lead time. 
In this paper, FCM is used as an effective solution method for $\mathrm{ABC}$ analysis for the first time. This solution method eliminates the criticism related to the subjectivity involved in weighing the criteria at the classical multicriteria $A B C$ analysis. FCM algorithm not only selects the inventory(ies) to care about mostly but also clusters all of the items according to their membership degrees. Consequently, FCM can be easily and efficiently applied to all sectors and all firms due to its flexibility. Under these circumstances, the FCM algorithm applied in this paper is a valuable alternative among the other modeling methods to any ABC analysis problem.

\section{References}

[1] F. Y. Partovi and M. Anandarajan, "Classifying inventory using an artificial neural network approach," Computers and Industrial Engineering, vol. 41, no. 4, pp. 389-404, 2001.

[2] C.-W. Chu, G. S. Liang, and C. T. Liao, "Controlling inventory by combining $\mathrm{ABC}$ analysis and fuzzy classification," Computers and Industrial Engineering, vol. 55, no. 4, pp. 841-851, 2008.

[3] R. Ramanathan, "ABC inventory classification with multiplecriteria using weighted linear optimization," Computers and Operations Research, vol. 33, no. 3, pp. 695-700, 2006.

[4] H. A. Guvenir and E. Erel, "Multicriteria inventory classification using a genetic algorithm," European Journal of Operational Research, vol. 105, no. 1, pp. 29-37, 1998.

[5] M. C. Yu, "Multi-criteria ABC analysis using artificial-intelligence-based classification techniques," Expert Systems with Applications, vol. 38, no. 4, pp. 3416-3421, 2011.

[6] B. E. Flores, D. L. Olson, and V. K. Dorai, "Management of multicriteria inventory classification," Mathematical and Computer Modelling, vol. 16, no. 12, pp. 71-82, 1992.

[7] O. Cakir and M. S. Canbolat, "A web-based decision support system for multi-criteria inventory classification using fuzzy AHP methodology," Expert Systems with Applications, vol. 35, no. 3, pp. 1367-1378, 2008.

[8] Y. Chen, K. W. Li, D. Marc Kilgour, and K. W. Hipel, "A case-based distance model for multiple criteria ABC analysis," Computers and Operations Research, vol. 35, no. 3, pp. 776-796, 2008.

[9] B. E. Flores and D. C. Whybark, "Implementing multiple criteria ABC analysis," Journal of Operations Management, vol. 7, no. 12, pp. 79-85, 1987.

[10] P. Zhou and L. Fan, "A note on multi-criteria ABC inventory classification using weighted linear optimization," European Journal of Operational Research, vol. 182, no. 3, pp. 1488-1491, 2007.

[11] W. L. Ng, "A simple classifier for multiple criteria ABC analysis," European Journal of Operational Research, vol. 177, no. 1, pp. 344-353, 2007.

[12] A. Hadi-Vencheh, "An improvement to multiple criteria ABC inventory classification," European Journal of Operational Research, vol. 201, no. 3, pp. 962-965, 2010.

[13] I. Al Kattan and A. Bin Adi, "Multi-criteria decision making on total inventory cost and technical readiness," International Journal Interaction Des Manufacturing, vol. 2, no. 3, pp. 137-150, 2008.

[14] D. Li, H. Gu, and L. Zhang, "A fuzzy c-means clustering algorithm based on nearest-neighbor intervals for incomplete data," Expert Systems with Applications, vol. 37, no. 10, pp. 6942-6947, 2010.
[15] G. E. Tsekouras and H. Sarimveis, "A new approach for measuring the validity of the fuzzy c-means algorithm," Advances in Engineering Software, vol. 35, no. 8-9, pp. 567-575, 2004.

[16] S. Lozano, D. Dobado, J. Larrañeta, and L. Onieva, "Modified fuzzy C-means algorithm for cellular manufacturing," Fuzzy Sets and Systems, vol. 126, no. 1, pp. 23-32, 2002.

[17] J. Kang, L. Min, Q. Luan, X. Li, and J. Liu, "Novel modified fuzzy c-means algorithm with applications," Digital Signal Processing, vol. 19, no. 2, pp. 309-319, 2009.

[18] Z. Yang, F. L. Chung, and W. Shitong, "Robust fuzzy clustering-based image segmentation," Applied Soft Computing Journal, vol. 9, no. 1, pp. 80-84, 2009.

[19] W. Yan, C. H. Chen, and M. D. Shieh, "Product concept generation and selection using sorting technique and fuzzy cmeans algorithm," Computers and Industrial Engineering, vol. 50, no. 3, pp. 273-285, 2006.

[20] Z. Hou, W. Qian, S. Huang, Q. Hu, and W. L. Nowinski, "Regularized fuzzy c-means method for brain tissue clustering," Pattern Recognition Letters, vol. 28, no. 13, pp. 1788-1794, 2007.

[21] A. B. Goktepe, S. Altun, and A. Sezer, "Soil clustering by fuzzy c-means algorithm," Advances in Engineering Software, vol. 36, no. 10, pp. 691-698, 2005.

[22] A. Azadeh, M. Anvari, B. Ziaei, and K. Sadeghi, "An integrated fuzzy DEA-fuzzy C-means-simulation for optimization of operator allocation in cellular manufacturing systems," International Journal of Advanced Manufacturing Technology, vol. 46, no. 1-4, pp. 361-375, 2010.

[23] I. Ozkan, I. B. Türkșen, and N. Canpolat, "A currency crisis and its perception with fuzzy C-means," Information Sciences, vol. 178, no. 8, pp. 1923-1934, 2008.

[24] S. A. Mingoti and J. O. Lima, "Comparing SOM neural network with Fuzzy c-means, K-means and traditional hierarchical clustering algorithms," European Journal of Operational Research, vol. 174, no. 3, pp. 1742-1759, 2006.

[25] H. Sun, S. Wang, and Q. Jiang, "FCM-based model selection algorithms for determining the number of clusters," Pattern Recognition, vol. 37, no. 10, pp. 2027-2037, 2004.

[26] G. A. Keskin, S. Ilhan, and C. Özkan, "The Fuzzy ART algorithm: a categorization method for supplier evaluation and selection," Expert Systems with Applications, vol. 37, no. 2, pp. 1235-1240, 2010. 

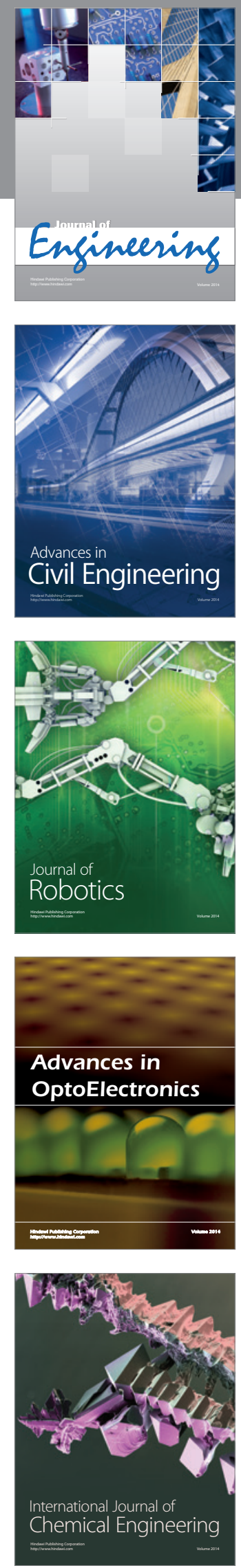

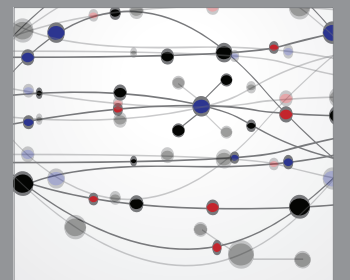

The Scientific World Journal
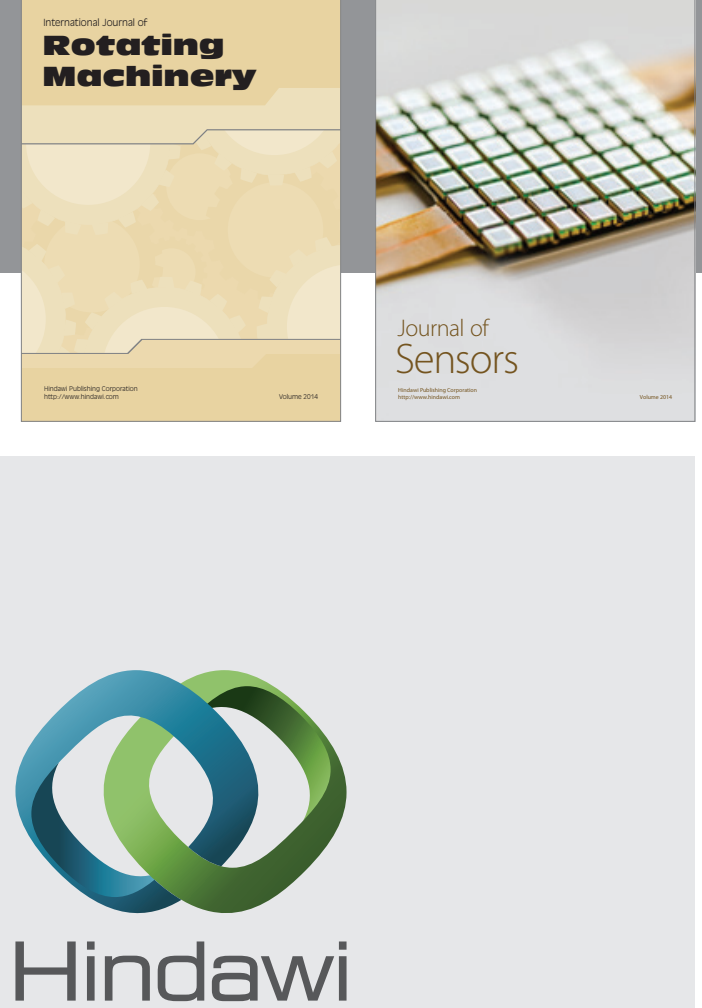

Submit your manuscripts at http://www.hindawi.com
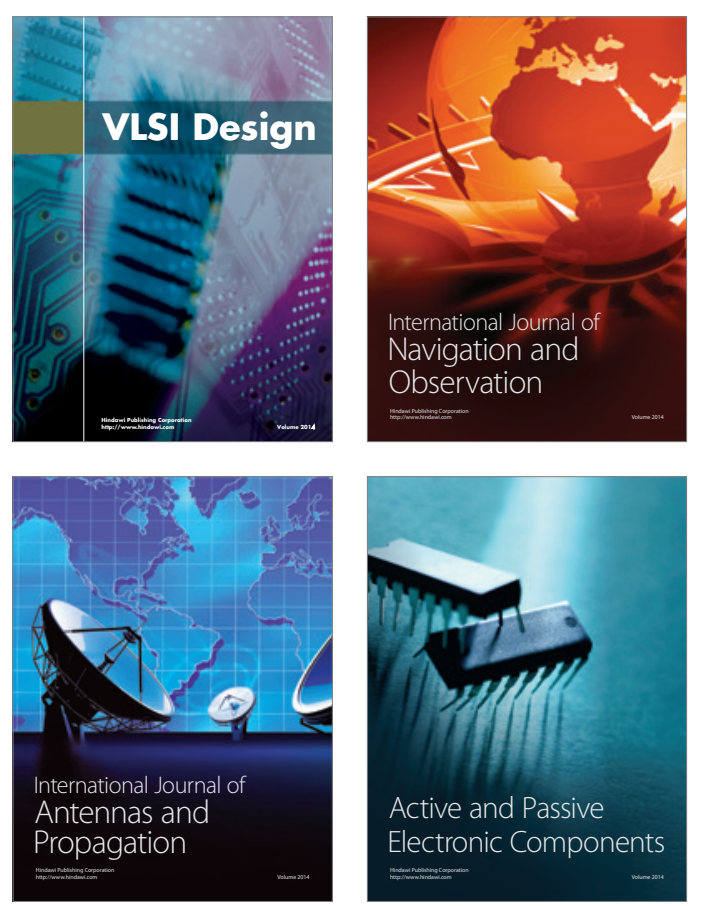
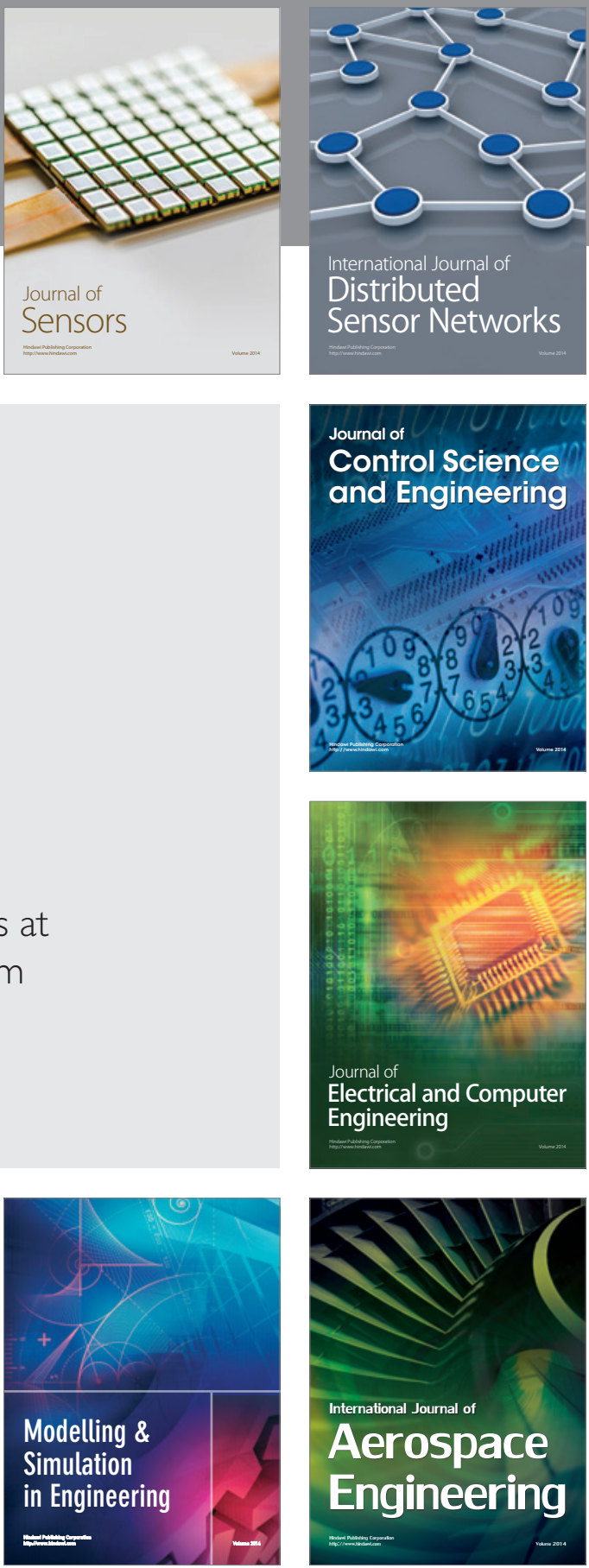

Journal of

Control Science

and Engineering
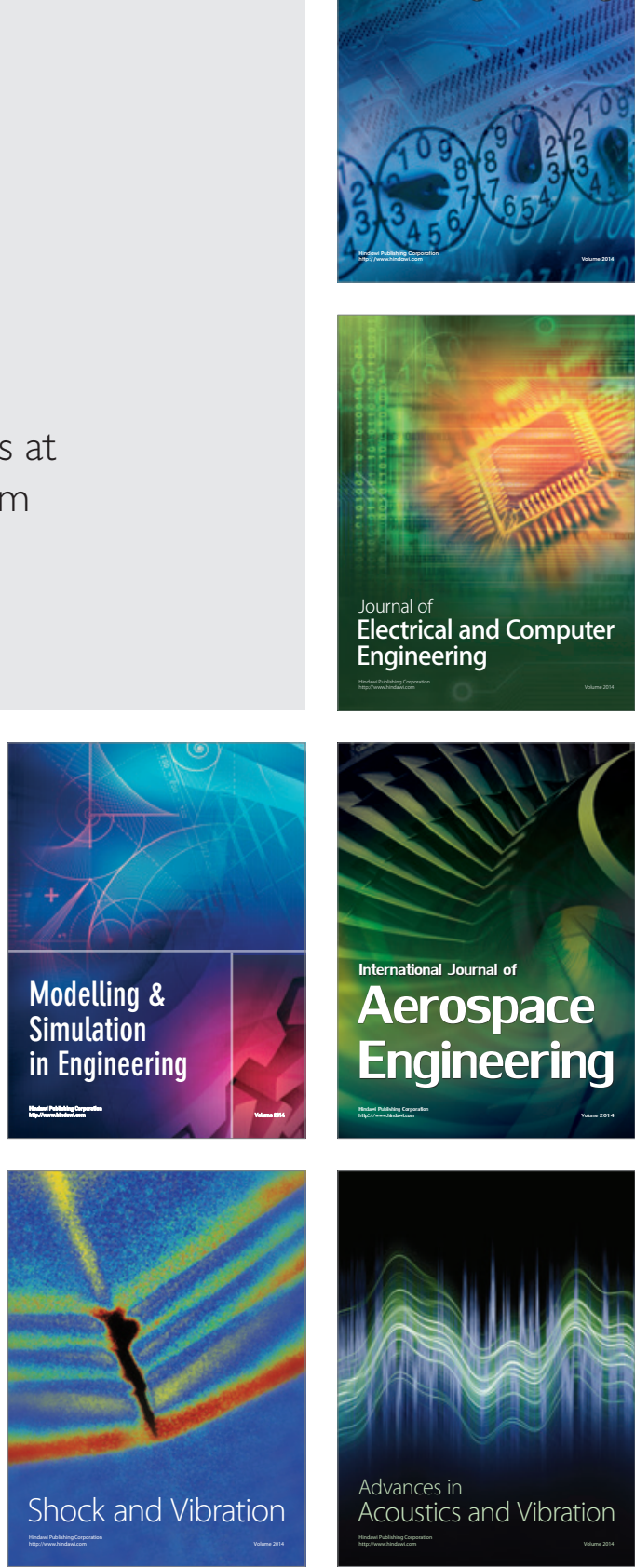